\title{
CONGENITAL TOXOPLASMOSIS IN AN AFRICAN CHILD
}

\author{
BY \\ D. B. JELLIFFE \\ From University College, Ibadan, Nigeria
}

(Received for Plblication Jlly 28. 1950)

Toxoplasmosis has been reported with increasing frequency during the last decade, and the various manifestations of the human disease, with particular reference to congenital toxoplasmosis, have recently been summarized by Hutchison (1949), and Wyllie, Fisher, and Cathie (1949). All the cases thus far have been reported from America or Europe, and the case of congenital toxoplasmosis described here is the first from Africa.

\section{Case Report}

A Yoruba boy, aged about 3 years, was brought to the Adeoyo Hospital, Ibadan, W. Nigeria, on February 3, 1950. The father complained that the child had diarrhoea, having his bowels open five times each day. Blood and mucus were present in the stools. Investigation showed this to be due to bacillary dysentery, which responded rapidly to oral phthalylsulphathiazole.

Also, it was noticed that the child had an enormous head and further investigations were undertaken to discover the cause.

The child was born at home. There was no history of any difficulty during labour. No illness had occurred during the neonatal period or infancy, save for an occasional attack of 'fever ' or diarrhoea. The first teeth had appeared at 9 months. The child walked at about 18 months, and was able to speak with simple sentences at about 2 years. (These figures are only approximate and could not be elaborated further.) No history of fits or paralyses or illness with unconsciousness was obtained.

The mother admitted of no history of any illness. She had had no other children and no miscarriages. Examination showed no abnormality. (The mother was very suspicious of the interest shown in her child and was convinced that a juju was being put on him. She therefore very likely withheld important facts.)

The parents had observed that the child's head was large a few months after birth. It had remained so ever since. They could not say whether it had increased markedly at any particular period, but were certain that there had been no increase in size in the previous six months.

Examination showed a well-nourished, pot-bellied boy (Fig. 1). He was $77.5 \mathrm{~cm}$. tall and weighed $23 \mathrm{~kg}$. The spleen was palpable (two finger breadths) and the liver edge could just be felt, but splenomegaly and hepatomegaly can be regarded as normal in a hyperendemic malarial town such as Ibadan. An occasional rhoncus could be heard in the chest. The apex beat was difficult to locate, but could be felt in the anterior axillary line.

The skull was greatly enlarged and box-shaped (Figs. 2 and 3). The circumference of the skull measured $60 \mathrm{~cm}$.

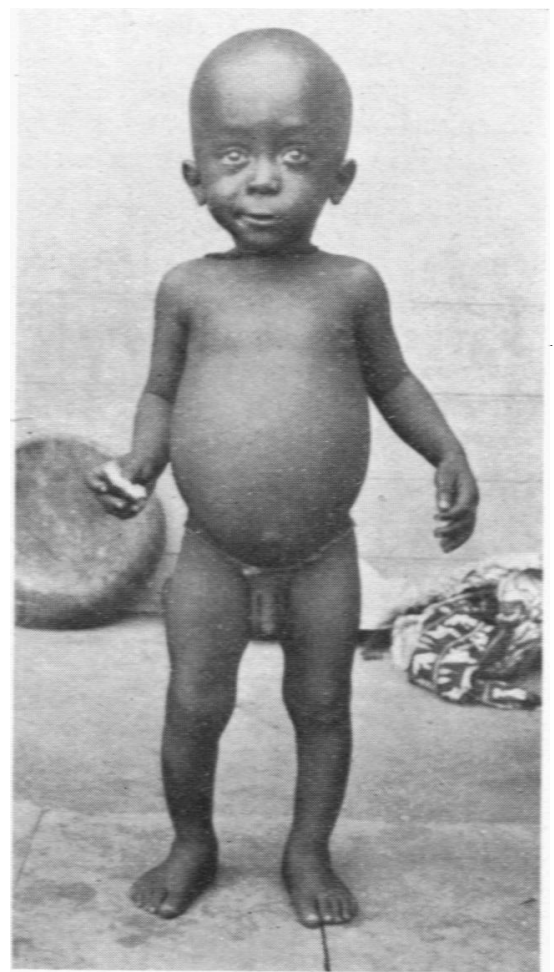

FIG. 1.-The child with congenital toxoplasmosis.

The anterior fontanelle was widely open (about $2 \cdot 5 \mathrm{~cm}$. long by $1.5 \mathrm{~cm}$. wide), and the sutures closed. There was no evidence of mental deficiency, cranial nerve palsy. visual disturbance, or paralysis. There were no clinical signs of rickets. 


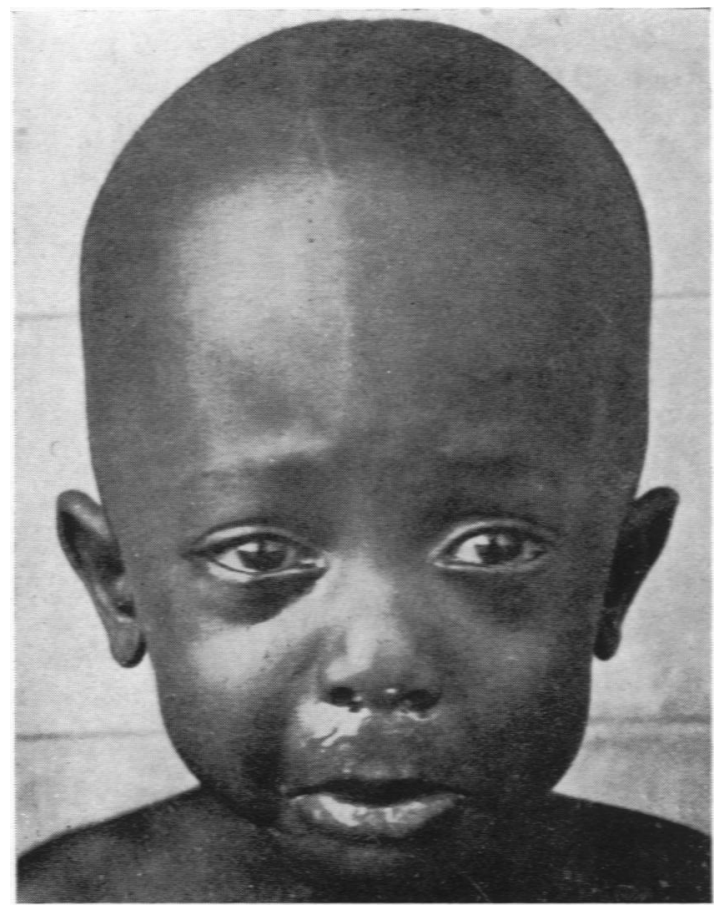

Fig. 2.-Front view of head.

Investigations. A blood count gave $\mathrm{Hb} .73 \%$; red blood count, 4,320,000 per c.mm.; C.I., 0.8; white blood count, 13,600 per c.mm. (polymorphs $43 \%$, metamyelocytes $11^{\circ}$, lymphocytes $46^{\circ}$ ).

The tuberculin patch test was negative at two, four, and six days.

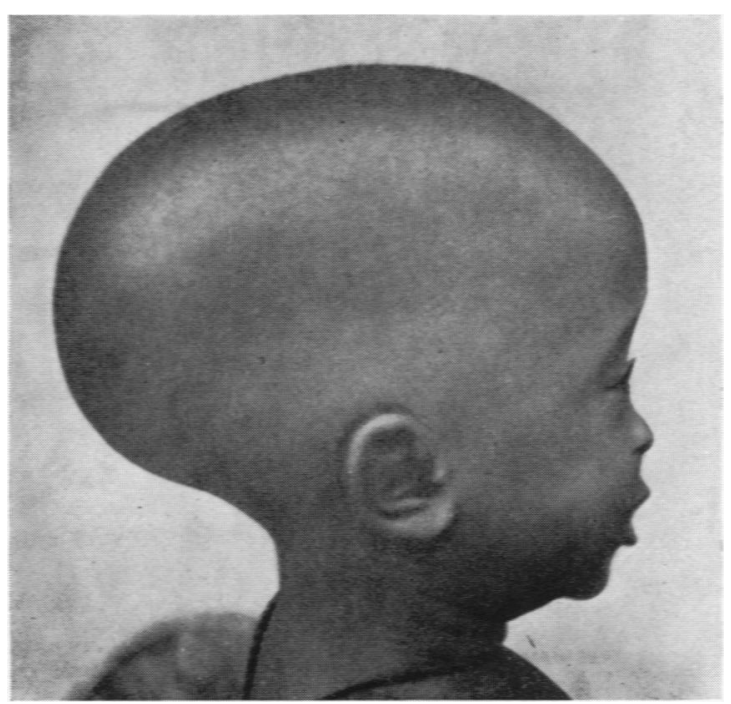

FIG. 3.-Lateral view of head.
Blood films taken on six occasions showed no malarial parasites.

Kahn tests were negative in both mother and child.

Stools were examined on six occasions, and ova of Ascaris only were found.

A radiograph of the wrists showed no rickets.

A lateral radiograph of the skull showed widely scattered areas of calcification, mainly of pin head size. Many were aggregated in small clusters. (Fig. 4 shows the distribution of the calcification.)

A radiograph of the chest showed a considerable degree of cardiac enlargement.

Lumbar puncture and air encephalograms were refused by the parents.

Dr. A. Dark reported that there was no abnormality in either eye, except that the right disc was hyperaemic. The lens and vitreous were quite normal. Both maculae were normal.

Serum from both the mother and the child was sent to Dr. Sven Gard, of the Statens Bakteriologiska Laboratorium, Stockholm, who reported:

- The sera from the mother and the child have been tested according to Sabin and Feldman (1948) with

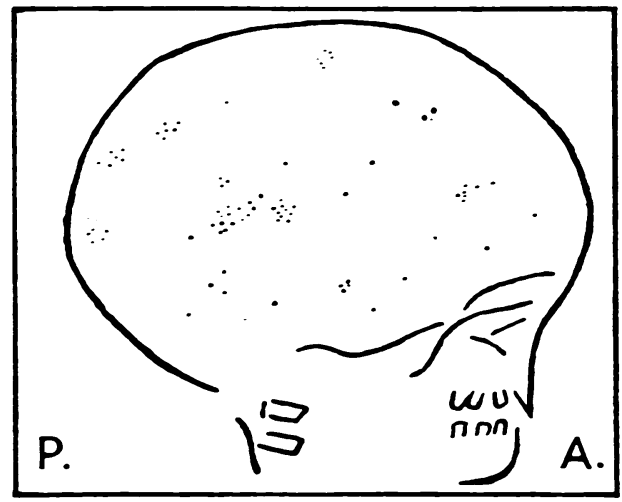

FIG. 4.-Diagram of radiograph of skull showing distribution of intracranial calcification.

positive results. The mother's serum titred 1:50, that of the child 1:2,000. These findings are strongly indicative of a diagnosis of congenital toxoplasmosis in the child. According to our experience from Swedish material a positive dye-test in children below the age of 10 years is never observed except in connexion with stigmata of a toxoplasmic nature. The titre value of the mother is well compatible with the assumption of an active toxoplasmosis - with or without clinical manifestations-three years ago. Titres usually rise to $1: 1,000$ or higher in the active stage of infection. In cases without complications a significant decrease is observed after about three months and a level of 1:50 can be attained within a year after the onset of infection.'

A further report (May 6, 1950) stated:

'A complement-fixation test has been carried out on the sera of the mother and child. Both gave positive results, that of the mother having a titre 1:4. On account of lack 
of serum, no complete titration of the child's serum was made. However, the highest dilution $(1: 8)$ tested gave a complete inhibition. These results are in good agreement with those of the previous test.'

Serum from both the mother and the child was sent to Dr. A. Macdonald, of the University of Liverpool, who reported:

' Both samples give positive complement-fixation tests with toxoplasma egg antigen. The titres were: mother $1: 20$ and child 1:30. The results of the dye-test and of the egg neutralization test were also positive.'

\section{Summary}

The main features of the reported case are (1) macrocephaly, possibly due to hydrocephalus, (2) radiological evidence of intracranial calcification, (3) cardiac enlargement, and (4) positive serological tests for toxoplasmosis from both the mother and the child. A diagnosis of congenital toxoplasmosis was made. It seemed probable that the infection had become either quiescent or healed.

This is the first case of congenital toxoplasmosis to be reported from Africa, all previous cases having been recorded in America or Europe.

I should like to thank Professor A. Brown, Department of Medicine, University College, Ibadan, for permission to publish this article.

My .thanks are especially due to Dr. Sven Gard and Dr. A. Macdonald for carrying out the serological tests, and to Dr. A. Dark for the ophthalmic opinion.

\section{REFERENCES}

Hutchison, J. H. (1949). Archives of Disease in Childhood, 24, 303.

Sabin, A. B., and Feldman, H. A. (1948). Science, 108, 660.

Wyllie, W. G., Fisher, H. J. W., and Cathie, I. A. B. (1949). Quart.J. Med., 19, 57. 